\title{
FEATURES OF THE COURSE OF ENAMEL BIOMINERALIZATION PROCESSES IN VARIOUS ANATOMICAL AREAS OF THE TOOTH
}

D0I: 10.36740/WLek202005105

\author{
Dmytro V. Kalashnikov' ${ }^{1}$ Petro A. Hasiuk ${ }^{2}$, Anna B. Vorobets' ${ }^{2}$, Svitlana 0. Rosolovska², Dmytro D. Kindiy ${ }^{1}$, \\ Anna 0. Hrad'2 ${ }^{2}$ Serhii G. Zubchenko' \\ 'UKRAINIAN MEDICAL STOMATOLOGICAL ACADEMY, POLTAVA, UKRAINE \\ 2. HORBACHEVSKY TERNOPIL NATIONAL MEDICAL UNIVERSITY, TERNOPIL, UKRAINE
}

\begin{abstract}
The aim: To establish the features of the structural organization of enamel in various anatomical areas of the tooth and determine their influence on the characteristics of the course of biomineralization processes.

Materials and methods: The study of the structural features of enamel and dentin was performed on thin sections of various groups of teeth. Then morphological, histochemical and electron microscopic examination methods were used.

Results: The study found that there are three structural and functional barriers to biomineralization of enamel, which are located in different anatomical areas of the tooth crown. Each of them has both general and specific features. Enamel biomineralization is a continuous process of exchange of calcium ions, donor of which is brushite. The stepwise process of biomineralization turns the latter into calcium octaphosphate, which then turns into hydroxyapatite. The latter, when destroyed by carbon dioxide, forms carboxyapatite. Conclusions: In the result of conducted study was established peculiarities of enamel mineralization processes in different anatomical parts of tooth.
\end{abstract}

KEY WORDS: enamel prisms, biomineralization, hydroxyapatite, pellicle

Wiad Lek. 2020;73(5):864-867

\section{INTRODUCTION}

According to statistics from the World Health Organization, damage to hard tissues of the teeth are the most common diseases of the oral cavity, the frequency of which in young and mature people reaches more than $90 \%$ [1]. A significant increase in the incidence of caries and non-carious lesions of hard tooth tissues in both the adult population and children poses the challenge for scientists and clinical dentists to search for new advanced methods of diagnosis, treatment and prevention of these diseases. But without the fundamental knowledge of the structural and morphological structure of the teeth it is impossible to solve this problem. To develop new principles and approaches to solving this problem, joint efforts of specialists in various fields of medicine, both medical and morphological, are required.

Today, the data of an experimental study of the structure of hard tissues of teeth, their morphological and histological structures are significantly expanded [2]. Further research in this area will offer new approaches to address the prevention, diagnosis and treatment of carious and non-carious lesions of hard tissues of different groups of teeth.

\section{THE AIM}

The aim of the research was to establish the features of the structural organization of enamel in various anatomical areas of the tooth and determine their influence on the characteristics of the course of biomineralization processes.

\section{MATERIALS AND METHODS}

This study was conducted at the orthopedic dentistry department I. Horbachevsky Ternopil National Medical University, Ukraine, and was approved by the ethics committee of the I. Horbachevsky Ternopil National Medical University. All procedures were carried out in accordance with the ethical standards of the responsible committee on human experimentation and with the Helsinki Declaration of 1975 , as revised in 2000 .

The study of the structural features of enamel and dentin was performed on thin sections of various groups of teeth removed according to orthodontic indications. Teeth with dental caries and non-carious lesions were excluded from the study. A complex of histochemical reactions was performed on the indicated preparations to reveal the peculiarities of the structure of tooth tissues. Preparation of solutions for carrying out a complex of histochemical reactions was carried out according to the recommendations of R. Lilly.

Colored thin sections were studied in transmitted and polarized light at various magnifications of the microscope and by electron microscopy.

\section{RESULTS}

According to the modern, odontoglyphic classifications, the surface of the tooth crown consists of elevated and 
deepened enamel sections, which are formed during embryogenesis of the tooth follicle [1].

As a result of morphological studies, we identified the histochemical structure of the elevated and deepened areas of the tooth crowns. So, in the focus of the fossae, the main grooves and additional grooves, there is a Schiff-iodic-acid-positive granular substance. In the area of the fossae and main grooves, it is surrounded by duplicates and in additional grooves by invagination of the cuticular epithelium, which is a derivative of the pulp epithelium of the enamel organ.

As a result of a histochemical study of tooth enamel, it was found that enamel prisms consist of heads and tails. The heads fit snugly together and look like parallel rhombuses. The tails of the enamel prisms of the first layer are connected to the heads of the next adjacent layer. After the layer of enamel prisms is a layer of atrophic ameloblasts. It is represented by thin, long and parallel stripes. The latter are divided among themselves by equal thin slits.

As a result of a number of studies conducted by several authors [3,4], it was found that due to the first contact of salivary fluid with the surface of the tooth, which has just erupted, a pellicle appears which is represented by a thin film of salivary glycoproteins, and forms within 20-30 minutes. It has a selective permeability, providing the process of diffusion of calcium ions into tooth enamel, and protects it from the action of chemical factors $[5,6]$.

According to modern research, octacalcium phosphate is a precursor of biological mineralization. In electron microscopic examination, calcium octaphosphate particles consist of thin plates, several nanometers in size, which resemble light, thin filamentary structures on the scanned sections, intertwined in the form of sockets $[7,8]$.

It has been established by A. Hasiuk et al. that calcium octaphosphate occupies an intermediate position between hydroxyapatite, dicalcium phosphatanhydrite and dicalcium phosphate hydrate. The last two calcium phosphates are contained in the aqueous layer of calcium octaphosphate, and the latter are located on the surface of hydroxyapatite enamel prisms $[9,10]$.

The works of A. Gurin $(2012)[11,12]$ it is proved that the enamel protein amelogenin, which is synthesized by ameloblast, promotes the transition of brushite into calcium octaphosphate. It is it that provides the transverse striping and ordering of the enamel prisms during embryogenesis.

In contrast to the deepened areas of the crown, protruding tubercles, rowing, and styles on the surface have a cuticular epithelium, which is almost completely obliterated at different ages. However, saliva micelles enriched with brushite and monetite cover preserved and atrophied ameloblasts. The latter, having bodies and processes, are interconnected. Between ameloblasts connected by a lock type, there are small slit-like spaces through which crystals of brushite can penetrate the enamel $[13,14]$. The latter has the structure in the form of beams of enamel prisms. During embryogenesis, the processes of ameloblasts have different orientations. So, with the opposite location of the processes, a spiral-like course of enamel prisms is formed, which on the section have the appearance of dark (parasons) and light (diazon) sections.

In the enamel thickness of the approximate surface of the crown of the tooth, the prisms have a stroke that resembles the intersection of bridge structures.

In the cervical region, enamel prisms have an s-shaped course and are included in individual segments of the lamellas. In our opinion, it is precisely due to the presence of the latter that brushite biological crystals penetrate into various parts of the enamel during mechanical load on the tooth during chewing. Directly the orientation of the prisms itself contributes to the most effective depreciation on the tubercles, then on the approximate sites. In the cervical areas of enamel, due to the reduction of the chewing load during food grinding, the depreciation function is performed to the least extent.

When conducting an electron microscopic study of enamel, it was found that at the boundary between the processes of ameloblasts in contact with salivary fluid and directly enamel prisms, there is a layer represented by lamellar filamentous structures that resemble the structure of calcium octophosphate.

In our opinion, due to the existing layer of atrophic ameloblasts, salivary fluid is filtered and forms the first biomineralization barrier in the protruding parts of the crown. Proof of this is the presence of a protein deposit on the surface of this layer.

Summing up the revealed features of the anatomical structure of enamel, it should be noted that, in contrast to the deepened areas where the cuticle is present on the tubercles, it is weakly expressed or completely absent. Therefore, in some areas of the tooth, there is another type of enamel biomineralization due to the presence of its cortical shiny layer. This provides a different degree of biomineralization of the protruding and recessed enamel sections.

Therefore, different parts of the tooth crown have three separate structural and functional barriers to enamel biomineralization.

The first is carried out by the cuticular epithelium of the deep sections of the crown of the tooth - there is a filtration of salivary fluid from protein deposit by means of a pellicle.

The second barrier is determined on the lateral and tubercles surfaces of the tooth enamel, in which the cuticle is erased or weakly expressed. At the same time, filtration is carried out through permeated atrophied ameloblasts of the cortical enamel layer.

A third structural and functional barrier to enamel biomineralization is located in the cervical region of the teeth. It is here that the gingival sulcus, filled with its fluid, is in contact with enamel and partially with cement. It has been established that on transverse sections, the gingival sulcus is lined with stratified squamous epithelium, and a well-defined cuticle is determined directly on the enamel surface. The epithelium of the gingival sulcus is located around the perimeter of the circular connection, which includes fibrous structures, fibroblasts and fibrocytes. The functional feature of the epithelial lining is the adsorption 
from salivary fluid of periodontal fluid and deposition of protein masses on the surface of the epithelium $[8,15,16]$. Sometimes minerals form white granular masses that are located in the gingival sulcus $[7,17,18]$.

Consequently, the presence of a stratified squamous epithelium and a cuticular epithelium in the gingival sulcus creates the prerequisites for a special biomineralization of the cervical enamel.

\section{DISCUSSION}

Thus, to summarize the process of biomineralization of enamel, we can come to the following conclusions:

1. Each of the three barriers identified by us has both common and specific features.

The general ones include the formation of a surface film - pelicula on the protruding and deepened areas of the tooth crown.

Pellicle in the fossa and fissure areas is represented by duplicates of the cuticular epithelium, on the approximate surfaces of the tooth crown - by a single-layer cuticular epithelium. In areas of tubercles and styles, the cuticle is partially erased and consists of atrophic ameloblasts.

The thin film of the pellicle contains glycoproteins that mark the residues of the monosaccharides combined via glucosidic bonds. Thanks to streptococcal glucosine transferases, sticky glycans are formed, which are able to fix brushite crystals with a wedge-shaped or triangular shape on the surface of the pelicule. They penetrate through the pellicle into the thickness of the underlying enamel surface to different depths.

2. As a result of the studies, it was established that, owing to various structural features of the structure of surfaces adjacent to the pelicula, enamel biomineralization processes occur. Thus, in the areas of the pits and fissures, due to the indentations in the thickness of the enamel, the largest amount of brushite occurs. The latter, with histochemical staining, is represented by red structures, and the cuticular epithelium, together with the pellicle, acquires a blue (alcian-positive) color due to acidic carboxyl and sulfhydryl groups. These groups provide hydrolysis of brushite, turning it into calcium octaphosphate.

On the approximate surfaces of the tooth crown, the cuticular epithelium is less pronounced. Therefore, in this area, the process of hydrolysis of the bruschite is poorly expressed.

On tubercles and styles where the cuticle is normally absent, the biomineralization process is carried out by atrophied ameloblasts and the synthesis of the dominant enamel protein amelogenin. Due to the effect of thixotropy, it is replaced by hydroxyapatite, which forms enamel prisms.

In the cervical region of the tooth crown, a stratified squamous epithelium filters salivary fluid from brushite crystals. Soluble calcium ions present in the periodontal fluid may react with the carbon dioxide released by the terminal processes of the odontoblasts. Thus crystals of carboxyapatite are formed. The latter is on the surface of enamel prisms and cement, and diffusing into the thick dentine forms a granular layer of Owen (interglobular dentin). It should be noted that the carboxyapatite crystals are placed in the form of a narrow strip of prism-free enamel along the enamel-dentin border, in areas of tubercles and the approximate surfaces of the reticular layer, which contains enamel protein - taftelin. The latter has the property of adsorbing crystals of carboxyapatite. In the intermediate layers of the enamel, among the prisms, there are filamentous and glomerular structures of calcium octaphosphate, which are precursors of the hydroxyapatite formation process.

Based on the research, the following enamel biomineralization scheme can be put forward:

1. Pellicle adsorption of bruschite crystals.

2. Hydrolysis of brushite with the morphological structures of the cuticle or flat stratified epithelium promotes the formation of crystals of calcium octaphosphate. It turns into hydroxyapatite and is located on the surface of enamel prisms. As a result of this transformation, the latter take the form of transverse striping.

3. In the zone of the enamel-dentin border, crystals of hydroxyapatite under the action of carbon dioxide are converted into carboxyapatite. The latter enters the dentin, forming reservoirs (lacunae) of interglobular dentin, which is further used for the biomineralization of dentin collagen.

\section{CONCLUSIONS}

Therefore, biomineralization of enamel is a continuous process of exchange of calcium ions, which are donated by bruchite. The stepwise process of biomineralization turns the latter into calcium octaphosphate, which then turns into hydroxyapatite. The latter, when destroyed by carbon dioxide, forms carboxyapatite. The presence of such an exchange of calcium ions indicates that enamel is a living tissue.

\section{REFERENCES}

1. Hasiuk P., Vorobets A., Hasiuk N. et al. Sex differences of odontometrical indexes crowns of molars. Interventional Medicine and Applied Science. 2017;9(3):160-163.

2. Hasiuk P.A., Kindiy D.D., Malyuchenko M.M. et al. Strukturni osoblyvosti budovy emalevo-dentynnoyi mezhi v riznykh dilyankakh koronky zuba [Features of the relationship of enamel prisms in different parts of the tooth crown]. Ukrainian Dental Almanac. 2011;6:3-5. (UA)

3. Hertel S., Schulz A., Lang R. et al. Activity and distribution pattern of enzymes in the in-situ pellicle of children. Arch Oral Biol. 2019;104:2432.

4. Zhang Y., Zheng J., Yu J. et al. Mechanical characterization of in vitroformed short-term salivary pellicle. J Biomech. 2018;66:194-197.

5. Zhang Y.F., Li D.Y., Yu J.X. et al. On the thickness and nanomechanical properties of salivary pellicle formed on tooth enamel. J Dent. 2016;55:99-104.

6. Zhang Y.F., Zheng J., Zheng L. et al. Effect of adsorption time on the adhesion strength between salivary pellicle and human tooth enamel. J Mech Behav Biomed Mater. 2015;42:257-266. 
7. Goss M., Socorro M., Monier D. et al. Trps1 transcription factor regulates mineralization of dental tissues and proliferation of tooth organ cells. Mol Genet Metab. 2019;126(4):504-512.

8. Zeng Q., Zheng J., Yang D. et al. Effect of calcium ions on the adsorption and lubrication behavior of salivary proteins on human tooth enamel surface. J Mech Behav Biomed Mater. 2019;98:172-178.

9. Hasiuk A.P., Dotsenko V.I., Hasiuk P.A. emal' zuba yak osoblyvyy stan ridkykh krystaliv [Tooth enamel as a special condition of liquid crystals]. Ukrainian Dental Almanac. 2012;6:8-12. (UA)

10. Skrypnykov P.M., Hasiuk A.P., Neporada K.S. Metabolizm, struktura i funktsii belkov emali (Chast' 1: belki emali: taftelin, enamelin) [Metabolism, structure and functions of enamel proteins (Part 1: enamel proteins: taftelin, enamelin)]. Ukrainian Dental Almanac. 2001;3:6-13. (Ru)

11. Gurin A.N., Komlev B.C., Fadeeva I.V. et al. Comparative study of the replacement of bone defects with osteoplastic materials based on a- and $\beta$-tricalcium phosphate. Stomatology. 2012;91(6):16-21.

12. Gurin A.N., Petrovich Yu.A., Komlev V.S. et al. Octacalcium phosphate. The metastable phase of mineralization of organic apatites. Russian Journal of Dentistry. 2012;3:4-6.

13. Jayasree R., Kumar T., Venkateswari R. et al. Eggshell derived brushite bone cement with minimal inflammatory response and higher osteoconductive potential. J Mater Sci Mater Med. 2019;30(10):113.

14. Zhang J., Wang L., Putnis C.V. Underlying role of brushite in pathological mineralization of hydroxyapatite.J Phys Chem B. 2019;123(13):2874-2881.

15. Gnatyuk M.S., Hasiuk P.A. Ul'trastruktura kutykuly ta pidlehlykh do neyi emalevykh pryzm koronky zuba [The ultrastructure of the cuticle and the enamel prisms of the tooth crown]. Achievements of clinical and experimental medicine. 2012;1:49-50. (UA)

16. Heller D., Helmerhorst E.J., Oppenheim FG. Saliva and serum protein exchange at the tooth enamel surface. J Dent Res. 2017;96(4):437-443.

17. Eckstein M., Vaeth M., Aulestia F.J. et al. Differential regulation of Ca2+ influx by ORAl channels mediates enamel mineralization. Sci Signal. 2019;12(578):46-63.

18. Ikeda Y., Neshatian M., Holcroft J. et al. The enamel protein ODAM promotes mineralization in a collagen matrix. Connect Tissue Res. 2018;59(1):62-66.
The work is a fragment of the research work of the orthopedic dentistry department I. Horbachevsky Ternopil National Medical University "Multidisciplinary approach to the study of the pathogenesis and treatment of main dental diseases based on the study of mechanisms of damage to the tissues of the oral cavity against the background of concomitant somatic pathology» (State Registration No. 0119U002431).

\section{ORCID and contributionship:}

Dmytro V. Kalashnikov - 0000-0002-6605-1957 ${ }^{A}$

Petro A. Hasiuk - 0000-0002-2915-0526 ${ }^{D}$

Anna B. Vorobets - 0000-0002-4119-7896 ${ }^{B}$

Svitlana O. Rosolovska - 0000-0003-4768-3905 ${ }^{E}$

Dmytro D. Kindiy - 0000-0003-2312-4981 C

Anna O. Hrad - 0000-0001-7625-4427 ${ }^{F}$

Serhii G. Zubchenko - 0000-0001-6909-7881 ${ }^{E}$

\section{Conflict of interest:}

The Authors declare no conflict of interest.

\section{CORRESPONDING AUTHOR Anna B. Vorobets \\ m.Voli St., 1, 46001, Ternopil, Ukraine \\ tel: +380968783459 \\ e-mail: vorobecab@tdmu.edu.ua}

Received: 21.01 .2020

Accepted: 01.04.2020

A - Work concept and design, B - Data collection and analysis, C - Responsibility for statistical analysis, D - Writing the article, $\mathbf{E}$-Critical review, $\mathbf{F}$ - Final approval of the article 